\title{
Composição química de Baccharis dracunculifolia, fonte botânica das própolis dos estados de São Paulo e Minas Gerais
}

\author{
Chemical composition of Baccharis dracunculifolia, the botanical source of propolis from \\ the states of São Paulo and Minas Gerais, Brazil
}

\author{
Severino Matias de Alencar ${ }^{1}$ Cláudio Lima de Aguiar $^{2}$ \\ Julio Paredes-Guzmán ${ }^{3}$ Yong Kun Park ${ }^{4}$
}

\section{RESUMO}

A própolis é uma substância resinosa coletada pelas abelhas de diversas partes das plantas. Sua composição depende da época, vegetação e local de coleta. Análises fitoquímicas de própolis produzidas de Baccharis dracunculioflia (alecrim-do-campo) por abelhas Apis mellifera africanizada nos estados de São Paulo e Minas Gerais foram feitas por espectrofotometria na região $U . V$.Visível, CCDAE-FR, CLAE-FR e CG-EM. Uma característica dos compostos fenólicos das própolis analisadas e da espécie vegetal de B. dracunculioflia foi a alta proporção de artepilin $C$ e outros derivados do ácido cinâmico. Com base nas evidências fitoquímicas, B. dracunculifolia foi identificada como a principal fonte vegetal das própolis produzidas nos estados de São Paulo e Minas Gerais.

Palavras-chave: própolis, Baccharis dracunculifolia, origem botânica, compostos fenólicos.

\section{ABSTRACT}

Propolis is a resinous hive product collected by honeybees from plant sources. The composition of the propolis depends upon the season, vegetation, and the area of collection. Phytochemical analyses of propolis produced from Baccharis dracunculifolia (alecrim-do-campo) in the states of São Paulo and Minas Gerais by africanized Apis mellifera were done by RP-HPTLC, RP-HPLC and GC-MS, and the absorption spectra was measured by UV-visible spectrophotometry. A distinctive characteristic of propolis and B. dracunculifolia was that both had a high proportion of the phenolic compounds artepillin $C$ and others dihydrocinnamic acid derivatives. Based on phytochemical evidence, $\boldsymbol{B}$. dracunculifolia was found to be the main source of propolis produced in the states of São Paulo and Minas Gerais.

Key words: propolis, Baccharis dracunculifolia, botanical origin, phenolic compounds.

\section{INTRODUÇÃO}

A própolis é uma resina coletada por abelhas da espécie Apis mellifera de diversas partes das plantas como gemas vegetativas, gemas florais e exsudados resinosos (GHISALBERTI, 1979). A própolis vem se destacando na literatura pelas suas várias propriedades biológicas apresentadas, como atividade antimicrobiana (MARCUCCI et al., 2001), antiinflamatória (MONTPIED et al., 2003), cicatrizante (GHISALBERTI, 1979), anestésica (BURDOCK, 1998), antitripanossomal (CUNHA et al., 2004), anticariogênica (DUARTE et al., 2003), antiviral (BURDOCK, 1998), anticarcinogênica (ISHIKAWA et al., 2004), antioxidante (KUMAZAWA et al., 2004) e fitotóxica (JOHNSON et al., 1994). Além disso, também vem sendo utilizada pelas indústrias farmacêutica e alimentícia na forma de alimentos funcionais (ACKERMANN, 1991).

Na Europa, América do Norte e oeste da Ásia, a fonte dominante para a elaboração da própolis

\footnotetext{
${ }^{1}$ Departamento de Agroindústria, Alimentos e Nutrição, Escola Superior de Agricultura "Luiz de Queiroz" (ESALQ), Universidade de São Paulo (USP), CP 9, 13418-900, Piracicaba, SP, Brasil. Email: alencar@esalq.usp.br. Autor para correspondência. ${ }^{2}$ Universidade Norte do Paraná (UNOPAR), 86041-100, Londrina, PR, Brasil.

${ }^{3}$ Ciências de Alimentos, Faculdade de Engenharia de Alimentos, Universidade Estadual de Campinas (UNICAMP), Campinas, SP, Brasil.

${ }^{4}$ Bioquímica de Alimentos, Faculdade de Engenharia de Alimentos, UNICAMP, Campinas, SP, Brasil.
} 
é o exsudato do botão de álamo (Populus sp.) (MARKHAM et al., 1996; WOLLENWEBER \& BUCHMANN, 1997). Entretanto, na América do Sul, a espécie vegetal do gênero Populus não é nativa, existindo uma grande diversidade vegetal para a retirada de resina, o que dificulta a correlação da própolis com a fonte produtora. A dependência geográfica e vegetal da própolis é exemplificada nos trabalhos, como por exemplo, de própolis da América do Sul, Europa, China, Canadá e Espanha (KÖNIG, 1985; TOMAS-BARBERAN et al., 1993; BONVEHI \& COLL, 1994; PARK et al., 2004). Recentemente, PARK et al. (2000) classificaram as própolis brasileiras em 12 grupos e verificaram a existência de somente um tipo majoritário de própolis na região Sudeste do Brasil. Nesse estudo, os autores demonstraram a pouca diversidade vegetal dessa região para a retirada de resina pelas abelhas.

O melhor indicador da origem botânica da própolis é a análise da sua composição química comparada com a provável fonte vegetal. A determinação da origem geográfica e, principalmente, a origem botânica aliada à fenologia da planta hospedeira, faz-se importante no controle de qualidade e até mesmo na padronização das amostras de própolis para uma efetiva aplicação terapêutica.

O objetivo deste trabalho foi avaliar por meio de técnicas de análise fitoquímica, se a espécie vegetal de B. dracunculifolia (alecrim-do-campo), família Asteraceae, é a fonte vegetal utilizada pelas abelhas Apis mellifera para a elaboração da própolis produzida nos estados de São Paulo e Minas Gerais.

\section{MATERIAL E MÉTODOS}

As amostras de própolis de abelhas africanizadas da espécie Apis mellifera foram coletadas em municípios do estado de São Paulo (Mogi Mirim, Mogi Guaçú, Amparo, Socorro, Campos do Jordão e Pinhalzinho) e Minas Gerais (Belo Horizonte, Carvalhópolis, Bambuí, Juiz de Fora e Nova Lima), perfazendo um total de 58 amostras. As gemas vegetativas contendo a resina vegetal de $\boldsymbol{B}$. dracunculifolia foram coletadas nas cidades de Mogi Mirim e Campinas, estado de São Paulo, e Bambuí, estado de Minas Gerais. Os extratos etanólicos de própolis (EEP) foram preparados a partir da adição de $15 \mathrm{~mL}$ de etanol (80\%) a 2 gramas de própolis triturada e homogeneizada. A extração foi feita a $70^{\circ} \mathrm{C}$ por 30 minutos e sob agitação constante. Após isso, foi feita uma centrifugação a $7500 \mathrm{x} \mathrm{g}$, a $5^{\circ} \mathrm{C}$ por 10 minutos, e o sobrenadante transferido para tubos de ensaio (15 x $160 \mathrm{~mm})$. Ao resíduo do tubo de centrífuga, foram adicionados $10 \mathrm{~mL}$ de etanol (80\%), sendo feita mais uma extração. Os sobrenadantes obtidos das duas extrações foram homogeneizados e acondicionados a $5^{\circ} \mathrm{C}$. Os extratos metanólicos vegetais de $\boldsymbol{B}$. dracunculifolia (EMV) foram obtidos pela extração de 2 gramas de gemas vegetativas em $10 \mathrm{~mL}$ de metanol P.A. durante 30 minutos a $60^{\circ} \mathrm{C}$, seguida de centrifugação a $7500 \times$ g, a $5^{\circ} \mathrm{C}$, por 10 minutos. Os sobrenadantes obtidos foram, então, armazenados a $5^{\circ} \mathrm{C}$ até o momento das análises.

Os espectros de UV-visível dos extratos alcoólicos foram obtidos por meio da adição de uma alíquota de $25 \mu \mathrm{L}$ do EEP e EMV a 30mL de etanol (96\%) P.A. Os espectros de absorção foram determinados na faixa de comprimento de onda de 200 a $600 \mathrm{~nm}$. A cromatografia em camada delgada de alta eficiência em fase reversa (CCDAE-FR) dos extratos alcoólicos foi feita de acordo com os métodos descritos PARK et al. (2000) e ALENCAR (2002), onde $3 \mu \mathrm{L}$ do EEP e EMV foram aplicados em placas de $0,2 \mathrm{~mm}$ de espessura RP $18 \mathrm{~F}_{254} \mathrm{~S}$ (Merck Co.). Utilizou-se como sistema eluente etanol:água destilada $(55: 45, \mathrm{v} / \mathrm{v})$. As placas desenvolvidas foram observadas sob luz ultravioleta a $366 \mathrm{~nm}$.

As análises dos extratos alcoólicos por cromatografia líquida de alta eficiência em fase reversa (CLAE-FR) foram feitas de acordo com o método modificado de ALENCAR (2002) e PARK et al. (2004). Neste método, $20 \mu \mathrm{L}$ do extrato foram injetados em coluna de fase reversa YMC PACK ODS (250 x 4,6mm), instalada em um sistema de cromatografia líquida (Shimadzu Co.) composto por duas bombas LC-10ADVP, degaseificador DGU-2A, injetor automático SIL-10ADvp, detector de arranjo de fotodiodos SPD-M10A e forno de colunas CTO10Avp mantido a $35^{\circ} \mathrm{C}$. A fase móvel utilizada foi água/ ácido acético (19:1, v/v) (solvente A) e metanol (solvente B), com fluxo constante de $1 \mathrm{~mL} / \mathrm{min}$. O gradiente iniciou com $30 \%$ do solvente B até $40 \%$ de B em 15 minutos, $50 \%$ de B em 30 minutos, $60 \%$ de B em 45 minutos, $75 \%$ de B em 65 minutos, $85 \%$ de B em 85 minutos, $90 \%$ de B em 95 minutos e 30\% de B em 105 minutos. As substâncias foram identificadas pela comparação dos espectros de ultravioleta, obtidos através do detector de arranjo de fotodiodos e dos tempos de retenção obtidos para os padrões e para as amostras. Foram utilizados padrões autênticos de flavonóides, ácidos fenólicos (Extrasynthese Co.) e Artepillin C. Adicionalmente, pinobancsina, pinobancsina-3-acetato e o éster do ácido dimetil dialil caféico foram gentilmente cedidos pelo Dr. Eckhard Wollenweber, do Intitut fur Botanik der Technischen Hochschule, Alemanha. 
Alíquotas de $400 \mu \mathrm{L}$ dos extratos alcoólicos foram adicionadas a $1 \mathrm{~mL}$ de solução etérea de diazometano $\left(\mathrm{CH}_{2} \mathrm{~N}_{2}\right)$ para a metilação. As amostras permaneceram em banho de gelo por 4 horas para a completa metilação. Após este tratamento, adicionaram-se $300 \mu \mathrm{L}$ de diclorometano e filtraram-se as amostras. As amostras foram analisadas em um cromatógrafo gasoso CG $17 \mathrm{~A}$ (Shimadzu Co.) acoplado a um espectrômetro de massas QP 5000 (Shimadzu Co.). A coluna capilar usada foi a CBP5 (30m x $0,25 \mathrm{~mm} \times 0,25 \mu \mathrm{m}$ de espessura do filme) contendo $5 \%$ de fenil em HMDS. O detector usado utilizado foi um quadrupolo operando no modo scanning $(\mathrm{m} / \mathrm{z} 40$ 400). A programação de temperatura foi $50^{\circ} \mathrm{C}$ $(0,3 \mathrm{~min})$ a $285^{\circ} \mathrm{C}(15 \mathrm{~min})$, com um incremento de $6^{\circ} \mathrm{C} / \mathrm{min}$. As amostras $(0,6 \mathrm{~mL})$ foram injetadas por um injetor automático AOC-17, com injeção no modo splitless (tempo de abertura da válvula de $0,5 \mathrm{~min}$ ). A integração foi feita através do software específico do equipamento (QP5000 software). Flavonóides e ácidos fenólicos presentes foram identificados por comparação dos tempos de retenção e dos espectros de massa obtidos do CGEM de padrões autênticos analisados nas mesmas condições. Outros compostos foram identificados por comparação dos espectros de massas de cada pico comparado com os da biblioteca do equipamento (Willey139).

\section{RESULTADOS E DISCUSSÃO}

Após o processamento e análise das própolis coletadas nos estados de São Paulo e Minas Gerais quanto à aparência, coloração dos EEP e cromatografia em camada delgada de alta eficiência em fase reversa (CCDAE-FR), foi encontrado em $96 \%$ das amostras, o mesmo perfil descrito por PARK et al. (2000). Apesar da existência de outros tipos de própolis existentes naqueles estados, estes não foram incluídos devido à sua rara ocorrência.

Os resultados preliminares obtidos pela varredura do espectro na região UV-visível do EEP e EMV, demonstraram o mesmo espectro de absorção. Como pode ser visto na figura 1 , tanto o EEP quanto o EMV apresentaram absorção máxima semelhante de 300 e 299nm, respectivamente.

A cromatografia em camada delgada de alta eficiência mostrou um perfil muito semelhante entre o EEP e o EMV, quando irradiado a 366nm (Figura 2). Da mesma forma, os resultados obtidos pela cromatografia líquida de alta eficiência em fase reversa, também apresentaram um perfil químico similar entre o EEP e o EMV, sendo confirmados 18 substâncias químicas idênticas nas duas amostras (Figura 3). Os compostos 16 e 17 foram majoritários tanto na própolis quanto no extrato metanólico vegetal, sendo que um foi identificado como artepilin C (Figura 3). A presença de artepilin C em plantas de $\boldsymbol{B}$. dracunculifolia e própolis

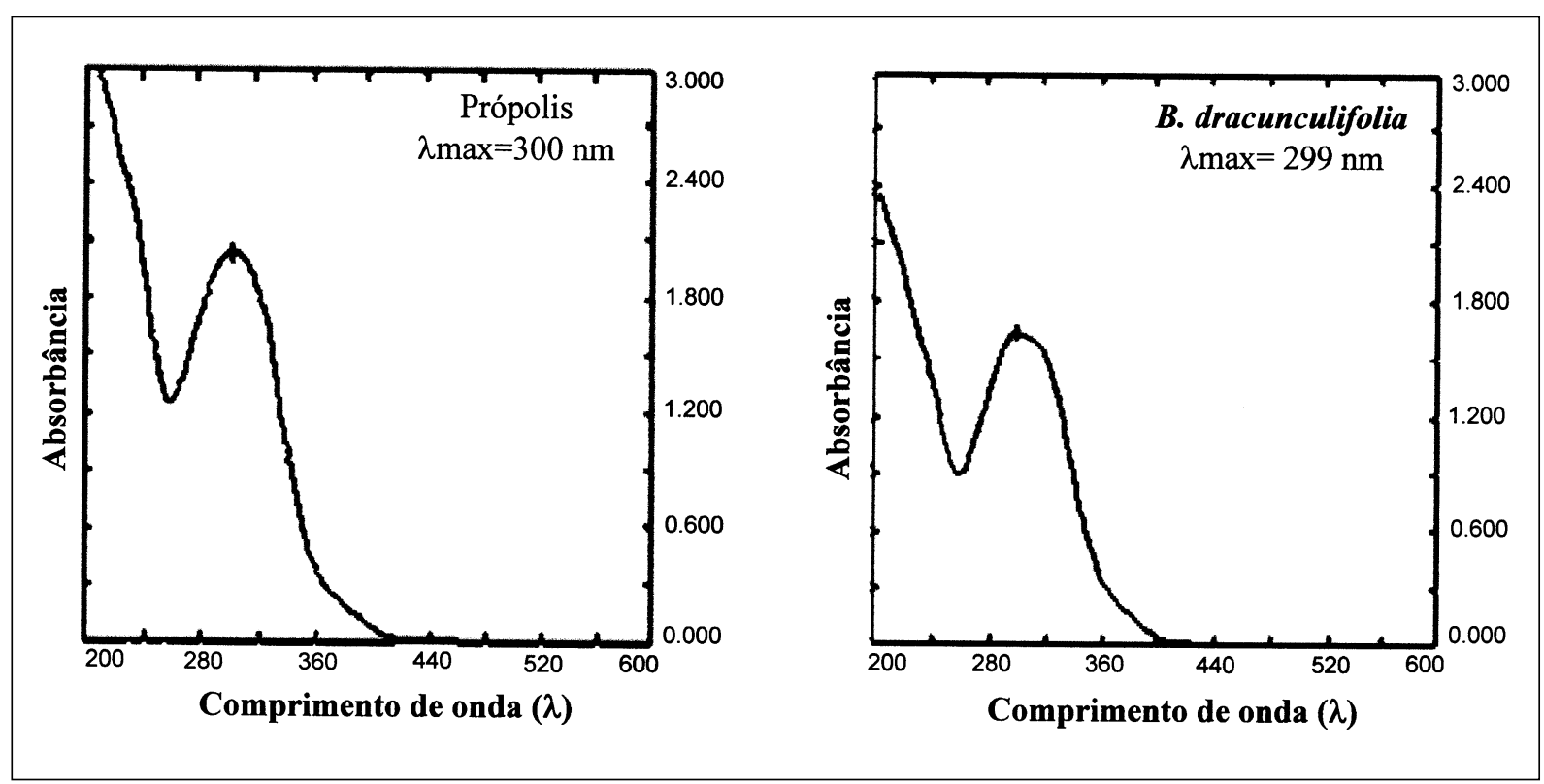

Figura 1 - Espectros de absorção na região UV-visível do extrato etanólico de própolis e do extrato metanólico vegetal de B. dracunculifolia.

Ciência Rural, v.35, n.4, jul-ago, 2005. 


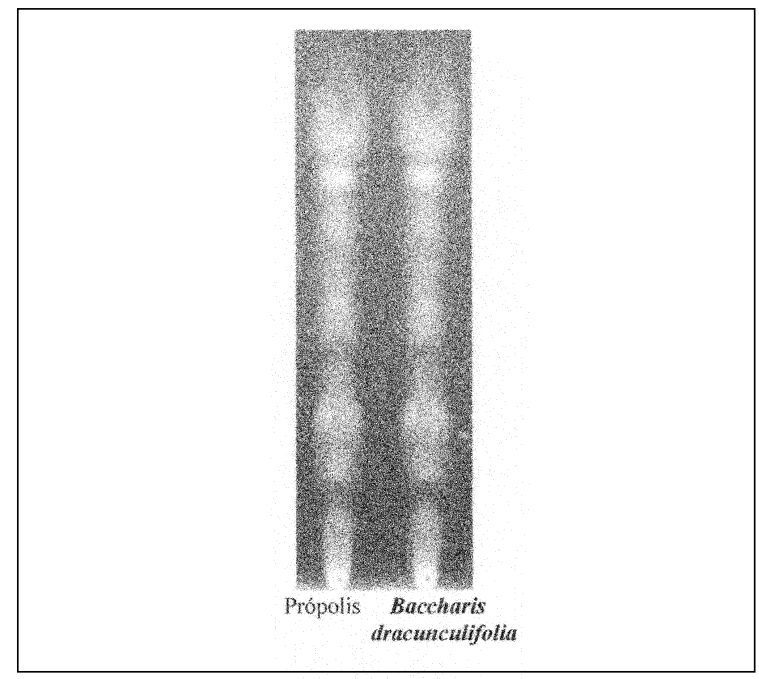

Figura 2 - Cromatografia em camada delgada de alta eficiência irradiada a 366nm, eluída com etanol:água (55:45 v/ v), das amostras de própolis e Baccharis dracunculifolia. de Minas Gerais também foi demonstrado por KUMAZAWA et al. (2003). Vários trabalhos sobre as evidências fitoquímicas da própolis do estado de São Paulo já foram realizados, entretanto os resultados não foram conclusivos quanto a sua origem vegetal (BANKOVA et al., 1995; BANKOVA et al., 1999). No estudo fitoquímico realizado entre a própolis brasileira e a espécie vegetal de $\boldsymbol{B}$. dracunculifolia, apesar de não ser mencionado de qual região ou estado do Brasil foram coletadas as amostras estudadas, ficou demonstrado a presença de uma grande diversidade de fenilpropanóides em comum nas amostras analisadas (BANSKOTA et al., 1998). Estudos fitoquímicos recentes também demonstraram fortes indícios de que a própolis do sudeste do Brasil tem a sua origem na espécie vegetal de B. dracunculifolia (PARK et al., 2004).

Os cromatogramas obtidos por meio da técnica de CG-EM permitiram identificar 18 substâncias comuns (Figura 4) entre o EEP e o EMV, que foram: 1etil éster do ácido etoxiacético: 132 (M+), 88 (36), 61

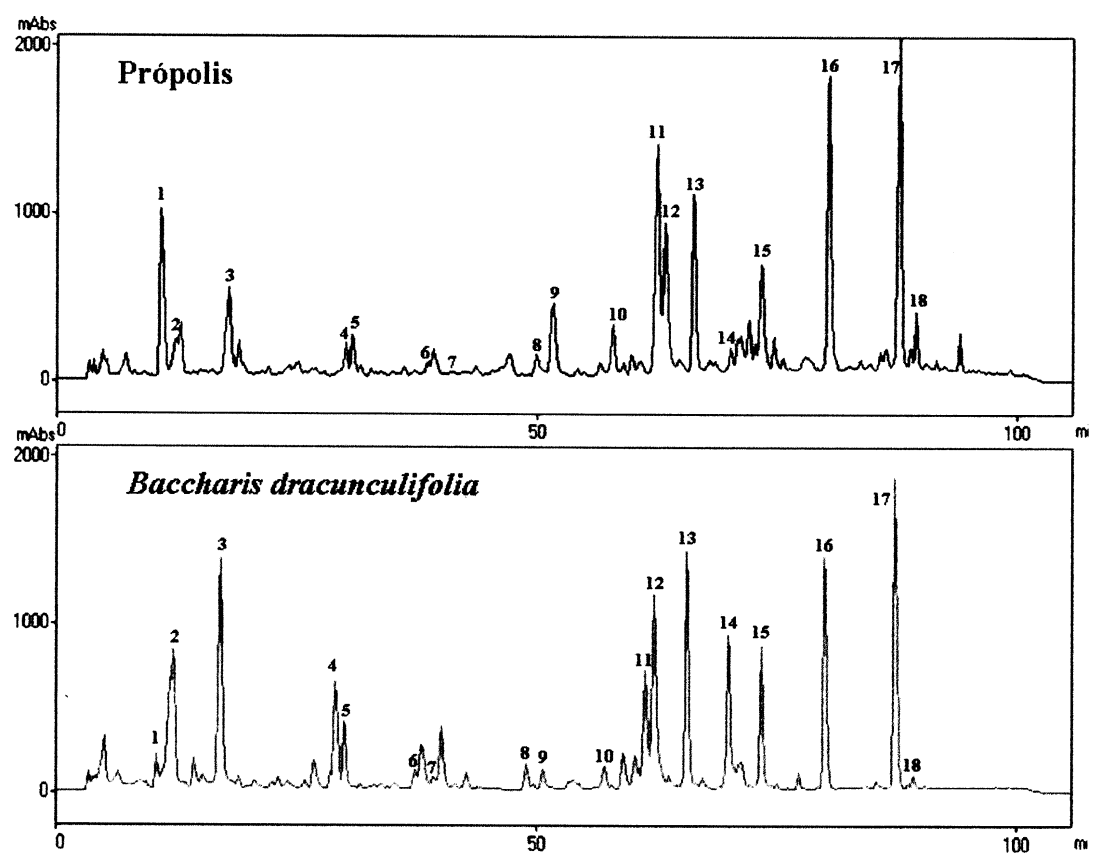

Figura 3 - Cromatografia líquida de alta eficiência do EEP e EMV (1=ácido cumárico; 2=ácido ferrúlico; $3=\lambda$. .254 nm; $4=$ ácido cinâmico; $5=$ pinobancsina; $6=$ canferol; $7=$ apigenina; $8=$ isosacuranetina; $11=$ canferide; $12=\lambda$ máx. $244 \mathrm{~nm}$; $16=$ artepelin $\mathrm{C} ; 17=\lambda_{\text {máx }} .223,276 \mathrm{~nm}$ ). (Volume de amostra injetada: $20 \mu \mathrm{L}$; detector utilizado: arranjo de fotodiodos a $254 \mathrm{~nm}$;

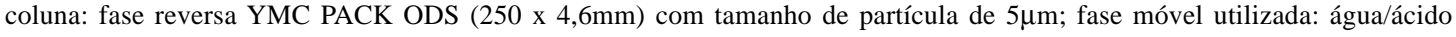
acético $(19: 1, \mathrm{v} / \mathrm{v})$ (solvente A) e metanol (solvente B) em sistema de gradiente, iniciando com $30 \%$ do solvente B até $40 \%$ de B em 15 minutos, $50 \%$ de B em 30 minutos, $60 \%$ de B em 45 minutos, $75 \%$ de B em 65 minutos, $85 \%$ de B em 85 minutos, $90 \%$ de B em 95 minutos e $30 \%$ de B em 105 minutos; vazão: $1 \mathrm{~mL}$ min $^{-1}$; temperatura da coluna: $35^{\circ} \mathrm{C}$ ).

Ciência Rural, v.35, n.4, jul-ago, 2005. 

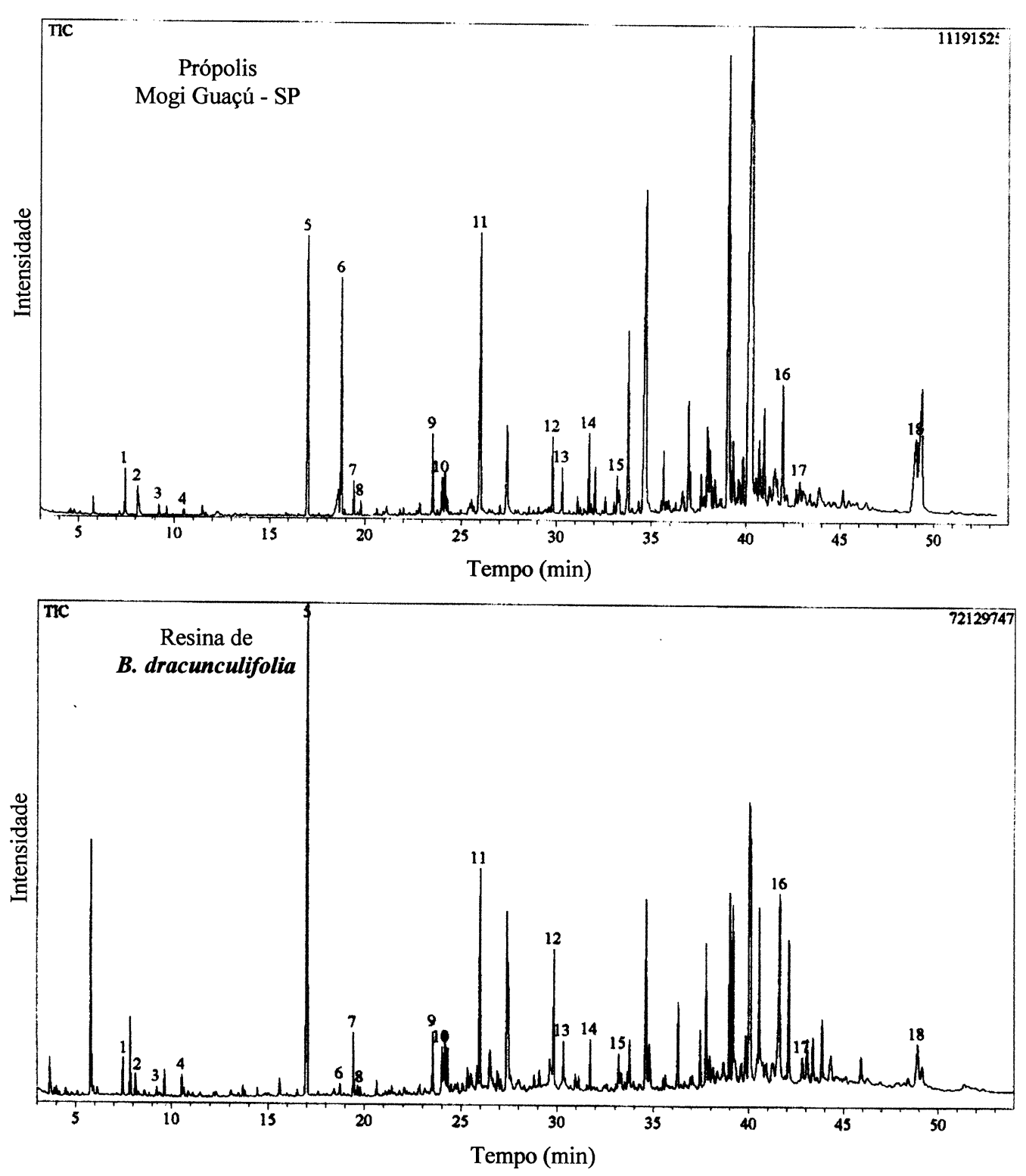

Figura 4 - Cromatografia gasosa acoplada com espectrômetria de massas (CG-EM) do EEP e EMV. (Volume de amostra metilada injetada: 0,6mL; tipo de injeção: "splitless"; coluna utilizada: coluna capilar CBP5 (30m x 0,25mm x 0,25mm); modo de operação do detector de massa: "scanning" ( $\mathrm{m} / \mathrm{z}$ 40-400); programação de temperatura do forno: $50^{\circ} \mathrm{C}(0,3 \mathrm{~min})$ a $285^{\circ} \mathrm{C}(15 \mathrm{~min})$, com um incremento de $\left.6^{\circ} \mathrm{C} \mathrm{min}^{-1}\right)$.

(18), $60(21), 59(100), 45(14), 42(16), 31(96), 29(70) ; 2-$ alfa-pineno: $136(6, \mathrm{M}+), 121(12), 93(100), 92(35), 91$ (27), $79(23), 77$ (30), $43(19), 41(33), 39(26), 27(26)$; $3-$ beta pineno $136(9, \mathrm{M}+), 121(12), 94(13), 93(100), 91$ (20), 79 (24), 77 (22), 69 (42), $53(16), 41$ (56), $27(22) ; 4-$ éster dimetílico do ácido butanedióico: $146(\mathrm{M}+), 115$ (71), 114 (20), 87 (18), 59 (73), 55 (100), 45 (14), 28 (27), 27 (27); 5- éster metílico do ácido hidroxicinâmico: 164
(34, M+), 105 (36), $104(100), 91$ (63), 79 (26), 78 (14), 52 (14), 51 (18); 6- éster etílico do ácido hidroxicinâmico: 178 (31, M+), 107 (44), 105 (44), 104 (100), 103 (15), 91 (58), 79 (22), 78 (18), 77 (26), 29 (11); 7 - éster metílico do ácido 4-metoxibenzóico: 166 (31, M+), 135 (100), 107 (13), 92 (20), 77 (27), 64 (15); 8- n-tetradecano: 198 (2, $\mathrm{M}+), 85(30), 71(48), 57$ (90), $56(14), 55(23), 43$ (100), 41 (59), 39 (16); 9- farnesol: 222 (M+), 107 (19), 93 (38), 
81 (20), 79 (16), 69 (84), 67 (24), 55 (34), 53 (15), 43 (62), 41 (100); 10- metil 4-hidroxihidroxicinamato: 180 (26, M+), 120 (33), 107 (100), 77 (9); 11- metil 4metoxicinamato (ácido cumárico): 192 (64, M+), 162 (11), 161 (100), 134 (14), 133 (33), 118 (13), 90 (13), 89 (17), 63 (18), 51 (10); 12- etil 3,4 dimetoxicinamato (ácido ferrúlico): 222 (100, M+), 207 (17), 191 (54), 147 (17), 77 (16), 51 (24); 13- éster metílico do ácido hexadecanóico: 270 (8, M+), 87 (58), 75 (18), 74 (100), 69 (13), 57 (16), 55 (25), 43 (37), 41 (30), 29 (18); 14- 1,1,3,3,4-pentametil-6butil-2,3-dihidroindeno: 244 (18, M+), 230 (20), 229 (100), 57 (10); 15- éster metílico do ácido 9,12octadecadienóico: 294 (M+), 109 (21), 96 (29), 83 (15), 82 (45), 81 (67), 80(20), 79(33), 69 (35), 68 (40), 67 (100), 55 (72), 54 (38), 43 (32); 16- apigenina: 314 (13, M+), 299 (15), 240 (24), 239 (100), 43 (22); 17 isosacuranetina: $300(53, \mathrm{M}+), 229(30), 193(18), 166$ (18), 138 (13), 138 (12), 135 (14), 134 (100), 121 (82), 119 (22), 65 (13), 44 (21); 18- canferide: 328 (100, M+), 327 (87), 309 (17), 285 (45), 150 (28), 135 (24), 77 (18), 69 (13), 44 (24). Entretanto, quando se compararam os picos não identificados do EEP e o EMV, observa-se o mesmo padrão de fragmentação, indicando assim que podem se tratar da mesma substância química. Também foi possível a identificação, tanto no EEP quanto no EMV de B. dracunculifolia, do composto farnesol o qual possui atividade citotóxica (VOZIYAN et al., 1995) e de apoptose celular (RIOJA et al., 2000). As amostras de própolis desses estados mostraram a existência de vários derivados do ácido cinâmico, principalmente, nas formas metil e etil ésters (Figura 4). BANKOVA et al. (1995) também relataram a existência de derivados do ácido cinâmico em amostras de própolis do estado de São Paulo. De acordo com os resultados obtidos pela técnica de CG-EM, pode-se dizer que o perfil das própolis desses estados é similar à resina de $\boldsymbol{B}$. dracunculifolia, tendo possivelmente a sua origem nessa espécie vegetal.

\section{CONCLUSÕES}

Os estados de Minas Gerais e São Paulo possuem somente um tipo majoritário de própolis, indicando assim que poucas são as espécies vegetais fornecedoras de resinas para elaboração de própolis. Pelo grande número de compostos identificados e confirmados pelas técnicas de cromatografia líquida de alta eficiência e cromatografia gasosa com espectrometria de massas, pode-se concluir que a resina da espécie vegetal de B. dracunculifolia é a principal fonte de resina para a elaboração das própolis produzidas nesses estados.

\section{AGRADECIMENTOS}

Os autores agradecem ao Dr. João Semir, do Instituto de Biologia da Unicamp, pela identificação da espécie vegetal Baccharis dracunculifolia e a Fundação de Amparo à Pesquisa do Estado de São Paulo (FAPESP), processo 98/001693 , pelo suporte financeiro.

\section{REFERÊNCIAS}

ACKERMANN, T. Fast chromatography study of propolis crudes. Food Chemistry, Oxon, v.42, n.2, p.135-138, 1991.

ALENCAR, S. M.. Estudo fitoquímico da origem botânica da própolis e avaliação da composição química de mel de Apis mellifera africanizada de diferentes regiões do Brasil. 2002. 120f. Tese (Doutorado em Ciência de Alimentos) - Faculdade de Engenharia de Alimentos, Universidade Estadual de Campinas.

BANKOVA, V. et al. Chemical composition and antibacterial activity of brazilian propolis. Zeitschrift fur Naturforschung C, Tubingen, v. 50, p. 167:172, 1995.

BANKOVA, V. et al. Phytochemical evidence for the plant origin of Brazilian propolis from São Paulo state. Zeitschrift fur Naturforschung C, Tubingen, v.54, p.401-405, 1999.

BANSKOTA, A. H. et al. Chemical constituents of brazilian propolis and their cytotoxic activities. Journal of Natural Products, Washington, v. 61, p. 896-900, 1998.

BONVEHI, J. S.; COLL, F. V. Phenolic composition of propolis from China and from South-America. Zeitschrift fur Naturforschung C, Tubingen, v. 49, n.11-12, p. 712-718, 1994.

BURDOCK, G. A. Review of the biological properties and toxicity of bee propolis. Food and Chemical Toxicology, Oxford, v.36, n.4, p.347-363, 1998.

CUNHA, I. B. D. S. et al. Antitrypanosomal activity of Brazilian Propolis from Apis mellifera. Chemical \& Pharmaceutical Bulletin, Tokyo, v. 52, n.5, p.602-604, 2004.

DUARTE, S. et al. Effect of a novel type of propolis and its chemical fractions on glucosyltransferases and on growth and adherence of mutans streptococci. Biological \& Pharmaceutical Bulletin, Tokyo, v.26, n.4, p. 527-531, 2003.

GHISALBERTI, E. L. Própolis: a review. Bee World, Cardiff, v.60, n.2, p.59-84, 1979.

ISHIKAWA, M. et al. Inhibition of growth and induction of apoptosis in human cancer cell lines by Propolis. Journal of Pharmacological Sciences, Kyoto, v.94, p.129-129, 2004 .

JOHNSON, K. S. et al. Chemical-compositing of NorthAmerican bee propolis and biological-activity towards larvae of greater wax moth (Lepidoptera, Pyralidae). Journal of Chemical Ecology, New York, v.20, n.7, p.1783-1791, 1994. 
KÖNIG, B. Plant sources of propolis. Bee World, Cardiff, v.66, p.136-139, 1985.

KUMAZAWA, S. et al. Antioxidant activity of propolis of various geographic origins. Food Chemistry, Oxon, v.84, n.3, p.329-339, 2004

KUMAZAWA, S. et al. Direct evidence for the plant origin of Brazilian propolis by the observation of honeybee behavior and phytochemical analysis. Chemical Pharmaceutical Bulletin, Tokyo, v.51, n.6, p. $740-742,2003$

MARCUCCI, M. C. et al. Phenolic compounds from Brazilian propolis with pharmacological activities. Journal of Ethnopharmacology, Clare, v.74. n.2, p.105112,2001 .

MARKHAM, R. K. et al. HPLC and GC-MS identification of the major organic constituints in new Zealand propolis. Phytochemistry, Oxford, v.42, n.1, p. 205-211, 1996

MONTPIED, P. et al. Caffeic acid phenethyl ester (CAPE) prevents inflammatory stress in organotypic hippocampa slice cultures. Molecular Brain Research, Amsterdam, v.115, n.2, p.111-120, 2003.
PARK, Y. K. et al. Evaluation of brazilian propolis by both physicochemical methods and biological activity. Honeybe Science, Tamagawa, v.21, n.2, p.85-90, 2000.

PARK, Y. K. et al. Chemical constituents in Baccharis dracunculifolia as the main botanical origin of southeastern Brazilian Propolis. Journal of Agricultural and Food Chemistry, Washington, v.52, n.5, p. 1100-1103, 2004

RIOJA, A.; et al. Preferential induction of apoptosis of leukaemic cells by farnesol. Febs Letters, Amsterdam, v.467, n.2-3, p.291-295, 2000.

TOMÁS-BARBERÁN, F. A. et al. Phytochemical evidence for the botanical origin of tropical propolis from Venezuela. Phytochemistry, Oxford, v.34, n.1, p.191-196, 1993.

VOZIYAN, P.A. et al. Mechanism of farnesol cytotoxicityfurther evidence for the role of pkc-dependent signaltransduction in farnesol-induced apoptotic cell-death.
Biochemical and Biophysical
Research Communications, San Diego, v.212, n.2, p. 479-486, 1995.

WOLLENWEBER, E.; BUCHMANN, S.L. Feral honey bees in the Sonoran Desert: propolis sources other than poplars (Populus spp.) Zeitschrift fur Naturforschung C, Tubingen, v.52, n.7-8, p.530-535, 1997 